\title{
Analysis of the Ability of European countries to carry on the Refugee Crisis
}

\author{
Wei Jiang \\ School of North China Electric Power University, Baoding 071000, China;727105937@qq.com
}

Keywords: refugee crisis, Gray relational analysis, TOPSIS

\begin{abstract}
To solve the sudden influxes of European refugee crisis, we establish a migration model to resettle the rising number of refugees in EU with proper division. We determine metrics as the index value to describe the countries' capacity and the death rate to measure safe and efficient of movement. We select 14 countries as typical cases of recipient country to be studied. The index value is described by TOPSIS method combined with gray relational analysis. Through the data and statistics we find out the equation of the death rate, which is related to types of transportation, length of routes and total population of refugee. Quantize the attributes of themselves as well.
\end{abstract}

\section{Parameters}

We begin to concentrate on the specific factors which can either enable or inhibit the safe and efficient movement of refugees. The parameters we assume and use are shown in Table 1.

Table 1 Model Parameters

\begin{tabular}{cc}
\hline Parameter & Meaning \\
\hline $\mathrm{m}$ & The number of the objectives \\
$\mathrm{n}$ & The number of the criterion \\
$\mathrm{X}$ & The collection of Gray relational factors \\
$\xi \mathrm{i}$ & Gray relational coefficient \\
$\mathrm{ri}$ & The correlation degree \\
$\mathrm{Cij}$ & The weighed standard matrix \\
$\mathrm{s}$ & Distance between the plan and the solution \\
$\mathrm{f}$ & The queuing index value \\
\hline
\end{tabular}

\section{Countries and Parameters.}

We begin to develop a set of parameters to evaluate the countries' capacity, including resources available and number of entry points to refugee population. Basic data of each country is shown in Table 2. We neglect other factors which may influence the results.

Table 2 Basic situation

\begin{tabular}{ccccccc}
\hline No & Country & $\begin{array}{c}\text { Area } \\
\text { km2 }\end{array}$ & $\begin{array}{c}\text { Population } \\
\text { million }\end{array}$ & $\begin{array}{c}\text { GDP } \\
\text { Billion } €\end{array}$ & $\begin{array}{c}\text { GDP } \\
\text { growth }\end{array}$ & Unemployment\% \\
\hline 1 & Bulgaria & 110900 & 7.3000 & 275.00 & 0.0350 & 10.0556 \\
2 & Germany & 357031 & 80.5000 & 24824.00 & 0.0132 & 4.8000 \\
3 & Greece & 131957 & 11.1000 & 1610.00 & 0.0294 & 25.7750 \\
4 & Spain & 505124 & 46.7000 & 9217.00 & 0.0135 & 23.1444 \\
5 & France & 549087 & 65.6000 & 18127.00 & 0.0146 & 10.3444 \\
6 & Italy & 301338 & 59.7000 & 13652.00 & 0.0120 & 12.5667 \\
7 & Hungary & 93030 & 9.9000 & 886.00 & 0.0152 & 7.2750 \\
8 & Austria & 83858 & 8.5000 & 2726.00 & 0.0157 & 5.7333 \\
9 & Switzerland & 312685 & 38.5000 & 3331.00 & 0.0189 & 3.3000 \\
10 & Finland & 338150 & 5.4000 & 1648.00 & 0.0148 & 9.2111 \\
11 & Sweden & 449974 & 9.6000 & 3411.00 & 0.0230 & 7.7222 \\
12 & Britain & 244101 & 63.9000 & 19568.00 & 0.0170 & 5.5875 \\
13 & Iceland & 103000 & 0.3250 & 142.00 & 0.0211 & 4.3778 \\
14 & Norway & 385155 & 5.0800 & 4822.00 & 0.0206 & 4.0125 \\
\hline
\end{tabular}




\section{Gray Relational Analysis.}

A model is created to describe the countries' capacity. Since the relationship is complicated, Gray relational analysis combined with methods TOPSIS was applied.

The gray theory can provide a solution of a system in which the model is unsure and the information is incomplete. Since the inside factors are complex, it is also suitable for the multi-input problems.

Determine the evaluation objectives and criterion. We assume the number of the objectives to be $\mathrm{m}$ the number of the criterion to be $\mathrm{n}$.

$\mathrm{X}$ stands for the collection of Gray relational factors, let $\mathrm{x} 0$ be the reference series and $\mathrm{xi}$ be the compared series:

$$
\begin{aligned}
& x_{0}=\left\{x_{0}(k) \mid k=1,2, \cdots, n\right\}=\left(x_{0}(1), x_{0}(2), \cdots x_{0}(n)\right) \\
& x_{i}=\left\{x_{i}(k) \mid k=1,2, \cdots, n\right\}=\left(x_{i}(1), x_{i}(2), \cdots x_{i}(n)\right) \in X
\end{aligned}
$$

Where $i=1,2, \cdots, m$.

Gray relational coefficient. In order to compare the importance of the factors, we need to do a standard regression. After applying non-dimensional analysis to the two series, the Gray relational coefficient can be acquired as

$$
\xi_{i}(k)=\frac{\min _{s} \min _{t}\left|x_{0}(t)-x_{s}(t)\right|+\rho \max _{s} \max _{t}\left|x_{0}(t)-x_{s}(t)\right|}{\left|x_{0}(k)-x_{i}(k)\right|+\rho \max _{s} \max _{t}\left|x_{0}(t)-x_{s}(t)\right|}
$$

Where $\min _{s} \min _{t}\left|x_{0}(t)-x_{s}(t)\right|$ is the minimum value while $\max _{s} \max _{t}\left|x_{0}(t)-x_{s}(t)\right|$ is the maximum value.

It means the relational coefficient of the compared series to the reference series at the moment of $k$. And $\rho$ means discrimination coefficient, which values from 0 to 1.

Generally, the discrimination rate is proportional to the value of $\rho$.

The correlation degree. It is defined as

$$
r_{i}=\frac{1}{n} \sum_{k=1}^{n} \xi_{i}(k)
$$

It means the correlation degree of the objective $i$ to the ideal objective.

The analysis and estimation. According to the value of the gray correlation degree we acquired, the sequence can be assured and the final estimation can be showed and discussed. Through the definition of the correlation degree, the essential factors that influence the arrival of refugees are occurred and quantized.

\section{TOPSIS methods.}

To revise our results and sort our final sequence of the European countries' capacity, the TOPSIS is introduced. TOPSIS is a method for multi-objective-decision-making, which can be applied to comprehensive assessment of countries' capacity. The data which came from the standard evaluation was analyzed with TOPSIS.

TOPSIS is the Technique for Order Preference by Similarity to an Ideal Solution.

The process is presented as follows:

Vector programming method. Use this method to accomplish the decision matrix. The original matrix is $\boldsymbol{A}_{\boldsymbol{i}}$ while standardized matrix is $\boldsymbol{B}_{\boldsymbol{i j}}$. There is

$$
b_{i j}=\frac{a_{i j}}{\sqrt{\sum_{i=1}^{m} a_{i j}{ }^{2}}}, i=1,2, \cdots, n
$$

Then we have the weighed standard matrix $C_{i j}=\left(c_{i j}\right)_{\mathrm{m} \times \mathrm{n}}$. The weight matrix we assume to be the weight we have calculate through the gray relational analysis. Here we combine TOPSIS with gray 
relational analysis to accomplish a more accurate solution.

Find out the positive ideal solution $\boldsymbol{C}^{*}$ and negative ideal solution $\boldsymbol{C}^{0}$. As for the calculation, we divide the property value in two types as benefit type and the cost type. The method of calculation is different. Supposing that the property value of number $\boldsymbol{j}$ is $\boldsymbol{c}_{\boldsymbol{j}}{ }^{*}$ and $\boldsymbol{c}_{\boldsymbol{j}}{ }^{\boldsymbol{j}}$. Then we have

$$
\begin{gathered}
c^{*}{ }_{i j}=\left\{\begin{array}{l}
\max c_{i j}, j \text { is the benefit type of property, } \\
\min c_{i j}, j \text { is the cost type of property, }
\end{array} j=1,2, \cdots n\right. \\
c^{0}{ }_{i j}=\left\{\begin{array}{l}
\max c_{i j}, j \text { is the benefit type of property, } \\
\min c_{i j}, j \text { is the cost type of property, }
\end{array}\right]=1,2, \cdots n
\end{gathered}
$$

In the calculation of benefit type and cost type, we assume the unemployment to be the cost rate and other factors to be benefit type. The unemployment rate would decrease the capacity while others have positive effect.

After that, calculate the distance between the positive ideal solution and the negative ideal solution of different countries. Each country represents a plan. We have the expression of the distance between plan $d$ and the positive ideal solution as

$$
s_{i}^{*}=\sqrt{\sum_{j=1}^{n}\left(c_{i j}-c_{j}^{*}\right)^{2}}, i=1,2, \cdots m
$$

As for the negative ideal solution, it is

$$
S_{i}^{0}=\sqrt{\sum_{j=1}^{n}\left(c_{i j}-c_{j}{ }^{0}\right)^{2}}, i=1,2, \cdots m
$$

We ultimately gain the queuing index value of different countries, which represents the ratio of capacity to resettle the refugees as

$$
f_{i}^{*}=\frac{s_{i}^{0}}{s_{i}^{0}+s_{i}^{*}}, i=1,2, \cdots m
$$

\section{Conclusion}

Several methods are used to acquire the weight of factors and the index value of countries' capacity. We obtain the weight in different method, including entropy weight method, gray relational analysis, and the combination of two. We use the different results in the calculation of TOPSIS method and ran through the possible combination of them.

Table 3 shows the final index value of different countries.

Table 3 Results of Gray relational analysis and TOPSIS

\begin{tabular}{ccccc}
\hline No & Country & Gray weight & TOPSIS & capacity \\
\hline 1 & Germany & 0.5035 & 0.6038 & 1 \\
2 & France & 0.5809 & 0.5801 & 0.923332481 \\
3 & Britain & 0.4174 & 0.5732 & 0.900933708 \\
4 & Switzerland & 0.2603 & 0.4946 & 0.646312139 \\
5 & Sweden & 0.3359 & 0.4846 & 0.613840375 \\
6 & Norway & 0.2452 & 0.4802 & 0.599614017 \\
7 & Bulgaria & 0.2811 & 0.4718 & 0.572195131 \\
8 & Italy & 0.4374 & 0.4482 & 0.495959957 \\
9 & Iceland & 0.0889 & 0.3986 & 0.335019132 \\
10 & Spain & 0.6014 & 0.3883 & 0.30171749 \\
11 & Finland & 0.2229 & 0.3626 & 0.218552096 \\
12 & Austria & 0.0940 & 0.3621 & 0.216779104 \\
13 & Hungary & 0.1030 & 0.3378 & 0.137957746 \\
14 & Greece & 0.4557 & 0.3261 & 0.1 \\
\hline
\end{tabular}




\section{References}

[1]Francisco Rodrigues Lima-Junior,Luiz Cesar Ribeiro Carpinetti. Combining SCOR® model and fuzzy TOPSIS for supplier evaluation and management[J]. International Journal of Production Economics,2016,174:.

[2]Deepa Joshi,Sanjay Kumar. Interval-valued intuitionistic hesitant fuzzy Choquet integral based TOPSIS method for multi-criteria group decision making[J]. European Journal of Operational Research,2016,2481:. 